\title{
NILAI PENDIDIKAN ISLAM DALAM SYAIR SENI MEUSIFEUT UNTUK GENERASI MILENIAL
}

\author{
Saifuddin A Gani ${ }^{1 *}$, Zulfahmi2 ${ }^{*}$ \\ Jurusan Seni Pertunjukan \\ Institut Seni Budaya Indonesia (ISBI) Aceh \\ Jl. Transmigrasi, Gampong Bukit Meusara, Kec. Kota Jantho, Kab. Aceh Besar, Kode Pos 23911 \\ Aceh. Indonesia \\ Email: saifuddin@isbiaceh.ac.id,zulfahi@isbiaceh.ac.id
}

\begin{abstract}
Abstrak
Seni meusifeut merupakan merupakan salah satu kearifan lokal masyarakat Aceh dalam melantunkan syair-syair Aceh yang dipadukan dengan gerakan-gerakan yang khas. Seni meusifeut juga salah satu peninggalan kebudayaan Aceh yang mengandung ciri khas keislaman di dalamnya dan saat ini mulai memudar. Seni meusifeut biasanya dimainkan oleh kalangan remaja laki-laki dimana terdapat seorang syeh yang membacakan syair dan diikuti dengan gerakan-gerakan tertentu oleh anggotanya. Syair yang dibacakan dalam seni meusifeut mengandung berbagai macam nilai dan makna mendalam. Penelitian ini dilakukan untuk mengetahui nilai pendidikan Islam yang terkandung dalam syair meusifeut. Penelitian ini menggunakan metode kualitatif. Metode kualitatif dilakukan dengan dengan cara mengumpulkan informasi dengan penentuan objek dan topik, observasi, penentuan informan, wawancara, pengambilan data hingga analisis data yang terkait dengan dengan syait seni meusifeut. Lokasi penelitian di Desa Baet Mesjid Kecamatan Sukamakmur Kabupaten Aceh Besar. Fukos kajian dalam penelitian ini adalah menemukan nilai pendidikan Islam dalam syair seni meusifeut.
\end{abstract}

Kata Kunci: nilai, pendidikan,syair, meusifeut, milenial.

\begin{abstract}
The art of meusifeut is one of the local wisdoms of the Acehnese people in singing Acehnese poetry combined with distinctive movements. Meusifeut art is also one of Aceh's cultural heritage which contains Islamic characteristics in it and is currently starting to fade. The art of meusifeut is usually played by teenage boys where there is a sheikh who reads a verse and is followed by certain movements by the members. The verses recited in the art of meusifeut contain various values and deep meanings. This research was conducted to determine the value of Islamic education contained in the meusifeut verse. This study uses a qualitative method. Qualitative methods are carried out by collecting information by determining objects and topics, observation, determining informants, interviews, collecting data to analyzing data related to the art of Meusifeut. The research location is in Gampong Baet Mesjid, Sukamakmur District, Aceh Besar District. The focus of the study in this research is to find the value of Islamic education in Meusifeut's art poetry.
\end{abstract}

Keywords: value, education, poetry, meusifeut, millennial.

\section{PENDAHULUAN}

Sejarah panjang masyarakat Aceh menunjukkan bahwa seni adalah sesuatu yang tidak terpisahkan dari masyarakat, dan perkembangan seni di Aceh mempunyai pasang surut. Hal ini dikarenakan terkadang seni memiliki keterkaitan dengan kondisi sosial politik. Kondisi masyarakat Aceh yang sering dilanda perang, dan juga konflik politik, ikut mempengaruhi expresi seni. Artinya senipun ikut dalam hal tertentu mendapat inspirasi dari sebuah kondisi sosial politik dari masyarakat yang melingkupinya. Hal ini tergambar dalam beberapa seni Aceh yang merefleksikan ini dalam berbagai ragam karya. Namun tetap di sisi lain, pesan-pesan agama juga menjadi bagian yang tidak terpisahkan, dan hampir selalu muncul dalam lagu-lagu atau syair-syair yang diciptakan. Seni dalam masyarakat berjalan seiring dengan perkembangan kebudayaan dan peradaban masyarakat Aceh itu sendiri.

Syair yang berkembang di Aceh sejak dulu sangat terikat dengan pesan-pesan agama di dalamnya. Salah satu syair yang berkembang di Aceh sejak dulu adalah seni Meusifeut yang di dalamnya mengandung pesanpesan agama yang disampaikan diiringi dengan gerakan tertentu. Adapun seni meusifeut merupakan 
Gorga : Jurnal Seni Rupa

Volume 10 Nomor 01 Januari-Juni 2021

p-ISSN: 2301-5942 | e-ISSN: 2580-2380

salah satu karya seni Aceh berupa susunan syair indah yang dibacakan oleh Syeh dan diiringan dengan gerakan dari anggota kelompoknya. Berbagai macam pesan dan nesehat terkandung dalam larik-larik Syair meusifeut diantaranya adalah pesan tauhid, ibadah, sholawat dan sejarah. Syair seni meusifeut yang disusun dalam bahasa Aceh dan sangat erat kaitannya dengan identitas agama Islam.

Seni meusifeut ini telah digalakkan disebagian daerah di Aceh dengan tujuan untuk menyampaikan pesanpesan ajaran Islam kepada anak-anak dan remaja. Seni Meusifeut dapat juga dikatakan sebagai sarana dakwah, karena di dalamnya mengandung ajaran Islam dengan materi yang disajikan memakai irama yang indah dan baitnya mengandung inti-inti ketauhidan, hukumhukum, keimanan dan syariat Islam. Hal ini juga menunjukkan bahwa adat dan kesenian Aceh tidak dapat dipisahkan dengan syariat dan ajaran Islam.

Asal usul kesenian meusifeut ini tidak diketahui dengan jelas, akan tetapi diperkirakan tumbuh dan berkembangnya kesenian ini seiring dengan berkembangnya agama Islam di Aceh, hal ini dibuktikan dengan materi yang terdapat dalam syair seperti sifat Allah, sifat Nabi, rukun Islam, rukun Iman, masalah ubudiah serta masalah muamalat. Materi meusifeut merupakan hasil karangan teungkuteungku atau ulama Aceh terdahulu yang diadopsi dari kitab-kitab Islam serta dirangkai dengan bahasa yang indah dan menarik. Bait-bait yang disusun dengan seni sastra yang indah akan menggairahkan bagi orang yang ingin menghafalnya dan memudahkan pengertiannya karena diubah kedalam bahasa Aceh.

Seiring dengan perkembangan zaman, seni meusifeut pada saat ini sudah mulai memudar dan bahkan hampir punah. Memudarnya seni meusifeut ini juga dipengaruhi oleh pengaruh budaya luar atau kemajuan teknologi. Memelihara dan melestarikan budaya, terutama budaya seni Meusifeut sangatlah sulit dengan melihat perkembangan dan perobahan pola kehidupan kaum milenial saat ini. Banyak kaum nuda yang sibuk dengan keperluan pribadinya, sehingga sedikit sekali waktu yang disisihkan untuk kegiatan yang lainnya, terutama melakukan kegiatan Meusifeut.

Tujuan utama dari seni meusifeut adalah menyampaikan syair-syair yang di dalamnya mengandung pesan-pesan ajaran Islam kepada pesertanya dan para pendengarnya. Selain itu seni meusifeut ini juga sering diperlombakan ataupun ditampilkan dalam even-even tertentu seperti dalam rangka memperingati hari-hari besar Islam ataupun acara-acara hajatan masyarakat. Beberapa upaya ini biasanya dilaksanakan untuk memotivasi para peserta dalam mengikuti kegiatan seni meusifeut dan sebagai syiar Islam dalam masyakat Aceh.

\section{KAJIAN TEORI}

Sejarah hidup manusia mencatat bahwa agama merupakan salah satu unsur yang sangat erat kaitannya dengan aspek sosial dan budaya masyarakat, termasuk kesenian. Walaupun ada kontentasi, tapi apresiasi Islam terhadap seni juga terlihat cukup kentara. Sejarah dakwah Islam, sejak masa rasul hingga saat ini, sangat berhubungan erat dengan seni, demikian juga sejarah dakwah Islam di Nusantara (Indo-Malayworld) yang menjadikan seni sebagai salah satu medium penyampaian informasi atau pesan dakwah. Apresiasi seni merupakan wacana alternatif untuk mendidik akal budi, yang mendorong dinamika dan keterlibatan masyarakat dalam interaksi budaya (Harun, 2012: 44). Agama perlu dipelajari dengan cara belajar yaitu kegiatan memperbaiki diri dari tidak tahu menjadi tahu (Azis, 2021).

Islam memandang bahwa Allah telah memberikan seperangkat kemampuan dasar yang memiliki kecenderungan berkembang yang menurut aliran psikologi behaviorisme disebut pre potence reflex (kemampuan dasar yang secara otomatis berkembang). Hal ini menunjukkan bahwa ada faktor alami yang selalu berpengaruh dalam pendidikan manusia khususnya anak-anak (Ismail. 2009: 65).

Sisi lain, seni merupakan perwujudan dari rasa keindahan pada umumnya, rasa keterharuan pada khususnya, serta kesejahteraan pikiran, sehingga ia menjadi sesuatu yang dapat disalurkan dan dapat dimiliki. Dalam kehidupan manusia sehari- hari, seni ini sangat diperlukan. Seni sangat identik dengan kepuasan, keindahan yang dirasakan batin, sehingga hampir setiap aktivitas yang dilakukan manusia memerlukan seni untuk melahirkan suatu nilai kerja yang memuaskan.

Secara umum dapat dikatakan, seni itu juga memperlihatkan hasil kerja seorang individu dan kelompok dalam beraktivitas. seni adalah semua yang menimbulkan rencana keindahan atau rasa keharuan dan semua yang diciptakan untuk melahirkan kesenangan. Dalam Islam aspek seni maupun kesenian sama sekali tidak ditolak, bahkan tidak ada dalil-dalil dan referensi yang mu'tabar yang menerangkan bahwa seni tidak dapat diterima (Muhammad, 2004: 87).

Islam membolehkan kesenian (sejauh tidak bertentangan dengan prinsip dan ajaran-ajaran agama). 
Kesenian yang identik dengan keindahan mendapat tempat dalam ajaran Islam. Islam itu indah dan menyukai kepada keindahan, dalam sebuah hadist disebutkan kutipan ini diambil dalam Akhwat (2013):

\section{"Sesungguhnya Allah SWT indah dan menyukai keindahan” (HR. Muslim),}

Berkaitan dengan budaya masyarakat di Aceh, sejarah mencatat bahwa faktor perekat yang paling kuat masa lalu adalah teologis, maknanya sangat kental akan agama dan adat. Syariat Islam yang telah dicanangkan dalam masyarakat Aceh, tidak hanya wacana tetapi juga kesadaran dan aplikasi moral seluruh masyarakat. Hal ini yang terekam dalam ungkapan Hadih Maja "Hukom ngen adat, lage zat ngen sifeut".

\section{METODE PENELITIAN}

Penelitian ini merupakan jenis penelitian kualitatif dengan menggunakan metode penelitian lapangan (field research), yaitu penelitian lapangan yang dilakukan dalam kancah sebenarnya. Pengumpulan data yang didapatkan dengan melakukan penelitian di tempat yang diteliti. Penelitian ini pada hakekatnya merupakan metode untuk menemukan secara khusus dari realita yang ada. Lokasi penelitian dilakukan di Desa Baet Mesjid, Kecamatan Sukamakmur, Kabupaten Aceh Besar.

Metode yang digunakan dalam menganalisis data adalah metode deskriptif analisis, yaitu penulis memberikan deskriptif mengenai subyek penelitian berdasarkan data variabel yang diperoleh dari kelompok subyek yang diteliti. Adapun yang dideskriptifkan dalam penelitian ini adalah nilai-nilai pendidikan Islam yang terkandung dalam syair seni meusifeut.

\section{HASIL DAN PEMBAHASAN}

\section{Hasil}

Berdasarkan hasil wawancara dan pengamatan langsung serta kajian dokumentasi yang dilakukan sebagai bagian dari penelitian ini, maka dapat dilihat bahwa dalam syair seni meusifeut mengandung beberapa nilai pendidikan Islam:

\section{1). Nilai Tauhid}

Mentauhidkan anak merupakan kewajiban orang tua kepada anaknya. Anak sebagai amanah dari Allah harus dididik orang tuanya terutama untuk mengenal Tuhannya. Salah satu caranya adalah dengan memperdengarkan kalimat tauhid yaitu dengan lantunan syair seni meusifeut yang mengandung nama Allah dilafalkan dengan irama yang khas. Hal ini akan membuat kalangan muda tidak bosan bahkan menjadi sebuah hiburan bagi mereka.

\section{2). Nilai Akhlak}

Salah satu unsur penting dalam pendidikan Islam adalah membentuk akhlak yang baik. Masyarakat Desa Baet Mesjid telah menggunakan media syair seni meusifeut sebagai salah satu media pendidikan akhlak untuk kalangan muda. Syair tentang pendidikan akhlak biasanya mengandung kisah teladan Nabi, Rasul dan orang sholeh.

\section{3). Nilai Kasih Sayang}

Dalam syair seni meusifeut juga terdapat unsur pendidikan kasih sayang. Diantara pesan kasih sayang yang disampaikan adalah kasih sayang orang tua kepada anaknya, kasih sayang anak kepada orang tuanya, kasih sayang terhadap lingkungan, Negara dan sesama manusia. Semua pesan pendidikan ini disampaikan dalam bentuk syair yang terstruktur.

\section{4). Nilai Ibadah}

Nilai ibadah dalam syair seni meusifeut tentunya disampaikan untuk mendidik kaum muda agar selalau rajin dalam beribadah sesuai ajaran Islam. Pesan terhadap nilai ibadah ini bukan hal yang tabu, mengingat bahwa sudah sebuah tradisi yang terjadi turun temurun bagi masyarakat Aceh yang sangat dekat dengan agama. Beberapa ibadah yang disampaikan dalam syair seni meusifeut ini adalah ibadah sholat, puasa, zakat, haji, berdo'a, bersedekah, tolong menolong dan cinta akan tanah air.

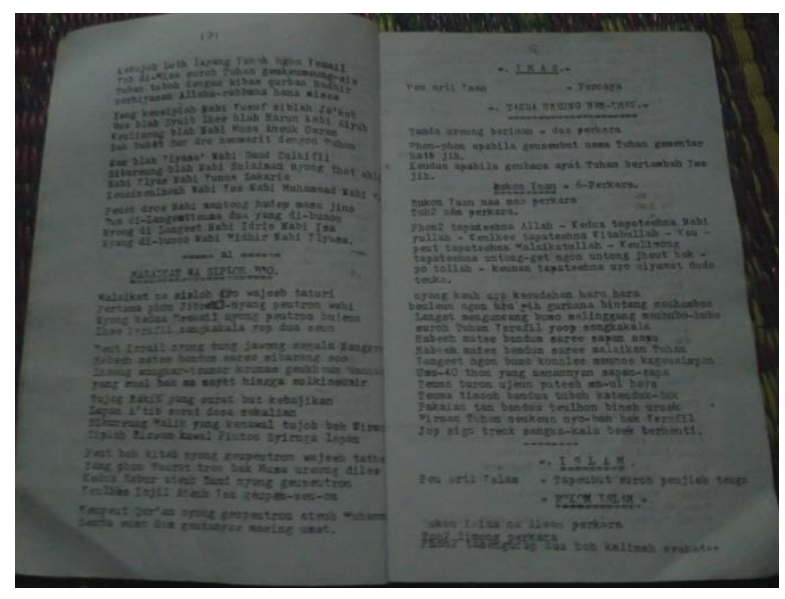

Gambar 1. Naskah Teks Syair Seni Meusifeut. (Afrizal, 2020)

\section{Pembahasan}

Sejarah kebudayaan Aceh telah dikenal bahwa banyak masyarakat Aceh yang ahli dalam membuat karya sastra, terutama sastra lisan. Masyarakat Aceh dapat menciptakan syair-syair secara spontan, kehandalan menciptakan syair secara spontan itu menjadi hal yang 


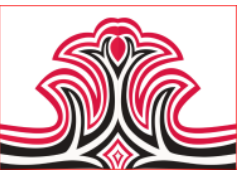

lazim yang membudaya hingga saat ini. Banyak persoalan atau hal tertentu yang kemudian diekspresikan melalui syair lisan. Kebiasaan masyarakat Aceh menciptakan puisi syair mungkin juga dipengaruhi oleh syair lisan dapat dikategorikan seperti seni meusifeut. Seni meusifeut merupakan salah satu jenis karya sastra lisan Aceh yang disampaikan dalam bentuk lisan yang dibacakan dengan irama khas dan diiringi dengan gerakan-gerakan terstruktur.

Seni meusifeut ini sudah berkembang di aceh seiring dengan perkembangan agama Islam di Aceh. Dimana kelompok seni meusifeut ini biasanya beranggotakan 15 orang dari kalangan anak-anak dan pemuda berjenis kelamin laki-laki yang dibimbing oleh pelatih atau tengku. Dalam hal ini tengkulah yang akan memilih anggota kelompok dan menentukan posisinya dalam kelompok seni meusifeut.

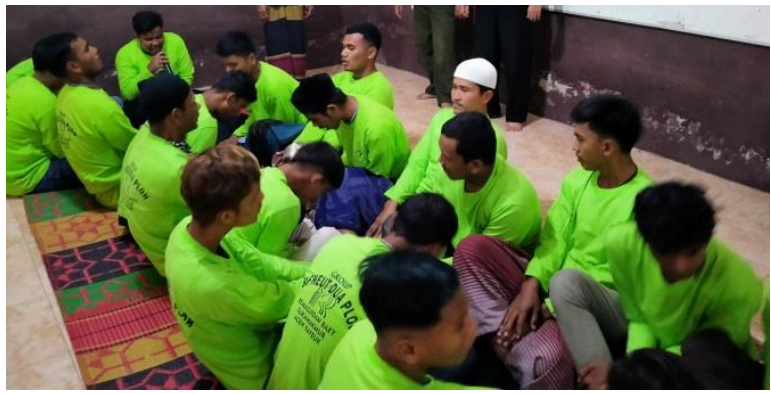

Gambar 2. Salah Satu Formasi Gerakan Seni Meusifeut (Afrizal, 2020)

Adapun pembahasan lain tentang pendidikan agama Islam dalam syair seni meusifuet adalah tentang sifatsifat Allah, sifat Rasul, nama rasul, nama malaikat, dan juga hokum-hukum dalam agama serta pelajaranpelajaran agama Islam lainya. Sebagai pembuka seni meusifeut juga menyampaikan puji-pujian kepada Allah dan syair yang mengandung motivasi belajar seperti pada sebuah syair yang diberi judul sepatah kata berikut ini :

\section{$=$ SEPATAH KATA $=$}

Ahamdulillah sekalian pujo

Keu Tuhan sidroe tempat kembali

Tuhan yang Peujeut langeut ngeun bumoe

Asoe nanggroe nyoe sama sekali

Tuhan yang peujeut laoet ngoen darat

Dum lat batat milik Robbana

Neupeujeut uroe ka deungon malam

Neupeujeut Adam ngoen Siti hawa

Syair tersebut merupakan pembuka dalam setiap penampilan seni meusifeut yang selanjutnya akan dilanjutkan dengan syair yang lain. Syair tersebut
Gorga : Jurnal Seni Rupa

Volume 10 Nomor 01 Januari-Juni 2021

p-ISSN: 2301-5942 | e-ISSN: 2580-2380

dibacakan dengan mengunakan irama dan diiringai dengan gerakan yang terstruktur. Setiap beda syair yang dibaca maka berbeda pula gerakan yang diperagakan oleh anggota kelompok. Latihan meusifeut dilakukan seminggu sekali dan biasanya diambil pada malam libur karena pesertanya rata-rata masih dalam pendidikan sekolah dan biasanya dilakukan pada malam minggu mulai setelah sholat isya sampai pukul 23.00 atau paling lama sampai pukul 00.00 WIB

\section{KESIMPULAN DAN SARAN}

\section{Kesimpulan}

Seni meusifeut merupakan salah satu kesenian Aceh yang di dalamnya mengandung beberapa nilai pendidikan Islam yang ditujukan kepada kaum muda selaku pelaku seni. Diantara nilai yang terdapat dalam syair seni meusifeut adalah nilai pendidikan tauhid, nilai Pendidikan akhlak, nilai pendidikan kasih sayang dan nilai pendidikan ibadah.

\section{Saran}

Berdasarkan penelitian yang telah dilakukan, peneliti berharap hasil penelitian ini nantinya dapat menjadi referensi dalam penelitian mauun informasi bagi akademisi dan masyarakat luas. Kaum muda selaku penerus bangsa harus tetap mendapat perhatian yang lebih untuk tetap melestarikan seni budaya dan tradisi lokal Aceh yang hampir terlupakan oleh masyarakat saat ini.

\section{DAFTAR RUJUKAN}

Afrizal. (2020). "Seni Meusifeut”. Hasil Dokumentasi: 12 Agustus 2020, Desa Baet Mesjid.

Akhwat, Keren. (2013). Sesungguhnya Allah SWT Indah dan Menyukai Keindahan. http://diahprameswari.blogspot.com/2013/10/ (diakses tanggal 27 Maret 2021).

Azis, A. C. K., Sugito, M. P., \& Mesra, M. S. (2021). Pengajaran Micro Teaching. Bandung: Media Sains Indonesia.

Harun, Mohd. (2012). Pengantar Sastra Aceh. Bandung: Citapustaka Media Perintis.

Ismail, Azman. (2009). Islam dan Budaya Aceh. Banda Aceh: Ar-Raniry Press.

Muhammad, Rusjdi Ali. (2004). Aceh Antara Adat dan Syariat. Banda Aceh: Ar-Raniry Press. 